\title{
Ignacio Arellano y Carlos Mata, Vida y obra de Lope de Vega, Madrid, Homole- gens (Bibliotheca Homolegens, 63), 2011, 334 pp. ISBN: 978-84-92578-72-2.
}

\section{Benedetta Belloni}

Università Cattolica del Sacro Cuore (ITALIA)

benedetta.belloni@unicatt.it

[Hipogrifo, (issn: 2328-1308), 1.1, 2013, pp. 277-282]

Recibido: 06-03-2013 / Aceptado: 17-03-2013

DOI: http://dx.doi.org/10.13035/H.2013.01.01.20

La presente monografía se inscribe en las investigaciones del proyecto TC/12, «Patrimonio teatral clásico español. Textos e instrumentos de investigación», en el marco del programa CONSOLIDER. Sus autores, Ignacio Arellano y Carlos Mata, respectivamente director y secretario del Grupo de Investigación del Siglo de Oro (GRISO) de la Universidad de Navarra, proponen un original y completo acercamiento a la biografía y a la obra de Félix Lope de Vega y Carpio (1562-1635). El objetivo del estudio es el de brindar al «discreto lector» (p. 7) un compendio de copiosas informaciones que procuran, tal como afirman los dos autores en el prefacio, «ofrecer una biografía clara y fundamental, acompañada de una introducción a su obra, porque la vida y la obra de Lope se hallan enredadas sin distinción posible» (p. 7). Basta con consultar de forma rápida el índice de la monografía para darse cuenta de que el trabajo de los dos especialistas se asienta esencialmente en la convicción de que el binomio vida-obra constituye un elemento indispensable a la hora de reconstruir la biografía del dramaturgo madrileño, acorde con el punto de vista de Teresa Ferrer al comentar que «Lope de Vega es un caso extremo de autor en el que vida y obra se interfieren hasta tal punto que la crítica ha llegado a ordenar su producción poética en función de sus ciclos vitales y amorosos»?

En este volumen, los dos autores incorporan ocho capítulos, más un prólogo y una coda final: el primer capítulo se dedica a la exposición de algunos de los hechos históricos más relevantes de la España de finales del siglo XVI y principios del XVII relacionados con la vida de Lope. Los seis capítulos centrales corresponden fundamentalmente a la narración de la parábola existencial del dramaturgo. El último refiere la trayectoria de la producción literaria del Fénix, destacando de forma detallada las tres líneas fundamentales de su Arte: poesía, prosa y teatro. Se subraya, además, que el bosquejo biográfico realizado por Arellano y Mata, tal como

1. Teresa Ferrer Valls, «Sustento, en fin, lo que escribí: Lope de Vega y el conflicto de la creación», Facundo Tomás e Isabel Justo (eds.), Pigmalión o el amor por lo creado, Barcelona, Anthropos, 2005, p. 99. 
precisan los mismos autores en el preámbulo (pp. 7-8), goza de unas doctas aportaciones extraídas de las contribuciones de ilustres especialistas de la materia. La ausencia de notas a pie de página y de referencias bibliográficas finales respalda la decisión autorial de que la monografía se estructure más bien como una asequible y cuidada selección antológica que sirva al lector como valioso instrumento para recomponer el complejo puzzle bio-bibliográfico lopesco.

Dentro del capítulo relativo al contexto histórico titulado «Algunas noticias sobre la España de Lope de Vega» (pp. 9-24), se articulan cinco breves secciones, empezando por «De la cima al declive». En esta primera parte, el relato de los acontecimientos históricos de la época filipina de finales del siglo XVI se entrecruza con el de los sucesos biográficos del autor madrileño, entre los cuales destacan, en particular, dos ocasiones bélicas (de las que se hablará también en los capítulos sucesivos): el alistamiento de Lope en la expedición del Marqués de Santa Cruz a la isla Terceira en 1583 y su participación en la Armada Invencible en 1588 a bordo del galeón San Juan. Como es sabido, ambas experiencias resultan inciertas por falta de pruebas documentales. La sección sigue adelante marcando unos puntos cruciales de la época de los Austrias menores, primero con relación a la regencia de Felipe III (la instauración del valimiento, la corrupta administración de Lerma y la expulsión definitiva de los moriscos) y luego también a la de Felipe IV (se alude sobre todo a la ferviente actividad política y reformista del Conde-Duque de Olivares), para terminar con una pincelada sobre la profunda crisis económica y social del siglo XVII que mucho influjo tuvo, tal como se explica con los dos últimos epígrafes («Camino al desengaño» y «La teatralización de la vida», pp. 23-24), en el origen de la angustiada concepción barroca del mundo.

Después de la parte introductoria sobre el marco histórico, los capítulos centrales de la obra muestran claramente la dinámica trayectoria narrativa adoptada por Ios autores: el relato de las etapas biográficas de Lope se acompaña siempre con la presentación de algunos fragmentos de su producción literaria y también con la combinación de otro tipo de aportaciones que contribuyen, en algunos casos, a esclarecer puntos desenfocados del recorrido vital del poeta y, en otros, a hacer que la narración de los sucesos sea más sugestiva. Es el caso del capítulo «Infancia, adolescencia y juventud: Ios años de formación» (pp. 25-49), en el que los autores tratan de reconstruir la fase inicial y decisiva del aprendizaje vital y literario del dramaturgo madrileño, no solo gracias a la voz del mismo Lope, sino también gracias a unos precisos pasajes de la Fama póstuma, obra que su discípulo y amigo Juan Pérez de Montalbán publicó en 1636 para rendir homenaje a la grandeza del maestro.

Acerca de la infancia del autor, Arellano y Mata remarcan que «son muy pocos los datos fidedignos de que disponemos» (p. 29). No obstante eso, los editores consiguen describir detalladamente el nacimiento y el bautismo, el origen santanderino de su familia, el periodo de niñez transcurrido en Madrid y la estancia juvenil en la capital hispalense en casa del tío inquisidor don Miguel del Carpio. Además, se concentra la atención en la fase de los primeros estudios del joven: se delinean el precoz amor por el arte poético transmitido por el padre bordador, las primeras 
clases impartidas por Vicente Espinel, quien le enseñó a «escribir en dos lenguas» (p. 35), y los años transcurridos en el Colegio Imperial, un instituto regido por los jesuitas en Madrid donde, por primera vez, asistió a unas representaciones teatrales. Los autores refieren, además, una curiosa anécdota relacionada a la etapa juvenil del Fénix: se trata del relato de la huida rocambolesca del dramaturgo hacia la región de León junto al amigo Hernando Muñoz en 1578, un episodio que demuestra explícitamente una adelantada «inclinación a la aventura del joven Vega» (p. 39) y que se presenta como conciso pero enriquecedor pormenor biográfico dentro del capítulo dedicado a la adolescencia del poeta. El mismo apartado termina con la mención a los supuestos estudios universitarios de Lope en Alcalá de Henares entre 1577 y 1582, a los que el poeta alude en varias ocasiones en sus versos, y de los que, sin embargo, como confirman Arellano y Mata, no queda huella en los registros complutenses. Finalmente cuentan los autores que, para finales de la década de los ochenta, Lope iba estableciendo sus personales parámetros como genial escritor hasta empezar a alcanzar cierta fama literaria en el escenario intelectual de la época.

A continuación, se exponen cuatro capítulos que corresponden al núcleo central de la evolución existencial y literaria de Lope. En el recorrido de su larga vida, como bien es sabido, un papel crucial lo desempeñó el aspecto sentimental. «Se ha llegado a sumar en el currículum amoroso del Fénix», comentan Arellano y Mata, «un total de trece mujeres "importantes" en su vida, con las que tuvo unos quince hijos, entre los legítimos y los bastardos» (p. 52): por esta misma razón, los dos autores apuntalan el relato biográfico del poeta madrileño con el robusto soporte de la narración de sus lances románticos. Tratándose de Lope, parece imposible renunciar a esta peculiar faceta de su vida puesto que «amor y literatura se darán la mano, se entrecruzarán continuamente en la biografía del Fénix y en su obra literaria» ( $p$. 51). En «De la pasión juvenil al primer matrimonio: Elena Osorio e Isabel de Urbina» (pp. 51-81) se expone sea el apogeo de la intensa pasión vivida con la «divina Filis», Elena Osorio, hija del empresario Jerónimo Velázquez, sea el desastroso declive de la misma historia por causa de una actitud obsesiva de celos del poeta. El resentimiento por una relación paralela emprendida por la joven con el acaudalado sobrino del cardenal Granvela llevó al Fénix a la difamación de Elena y de su familia a través de unos versos calumniadores que le costaron, primero, la cárcel y, luego, el destierro de la corte durante cuatro años. Ceder la palabra al mismo Lope es el recurso más valioso de que disponen los editores para relatar el inflamado amorío entre los dos.

El capítulo se adelanta con la exposición de la crónica del matrimonio reparador entre el poeta e Isabel de Urbina, mujer con la que Lope se había escapado de Madrid en 1588. Los años siguientes, a pesar del paréntesis de la supuesta implicación en el conflicto con la Armada, se describen como años de serenidad. La estancia en Valencia resulta propicia para Lope, de hecho, como bien subrayan AreIlano y Mata (pp. 72-74), la febril vida cultural de la capital levantina le proporciona gran inspiración para su arte dramático. Concluye el capítulo el relato del traslado del poeta y de su familia a Alba de Tormes en el palacio del Duque de Alba, donde asume Lope el cargo de secretario del noble señor, y donde vive también la tragedia 
de la muerte de su esposa. A finales del siglo, alrededor del año 1595, el Fénix vuelve a Madrid tras obtener el perdón de Jerónimo Velázquez, así como atestiguan los documentos proporcionados por los dos editores (pp. 78-79).

En el siguiente punto biográfico, Arellano y Mata se ocupan de relatar las segundas nupcias que Lope contrajo en 1598 con Juana de Guardo, hija de Antonio, rico abastecedor de Madrid. Los dos autores subrayan la idea de que fue un enlace de conveniencia y, para mostrar la ironía que el episodio suscitó en la comunidad literaria de la época, no olvidan proporcionar en el texto los famosos versos atribuidos a Francisco de Quevedo y destinados al dramaturgo madrileño: «sempiterno amancebado / casó con carne y pescado» (p. 84). A continuación, se cuentan los amoríos que Lope emprende, paralelamente a su relación matrimonial, con la actriz Micaela Luján, cuyos pseudónimos literarios, recuerdan los autores, fueron Lucinda o Camila Lucinda. En esta secuencia biográfica, Arellano y Mata refieren el sentimiento apasionado del Fénix hacia la bella mujer a través de la exposición de algunos poemas amorosos dedicados a ella y publicados en las Rimas y en La hermosura de Angélica. Los editores recalcan que, durante esta misma etapa de su vida, «Lope llevará una vida doble, manteniendo dos mujeres, dos familias, dos hogares. Irá creciendo el número de sus hijos, y crecerá iqualmente el de sus obras, junto con su fama y popularidad» (p. 92). Por estos años, vivía el poeta entre varias ciudades españolas (Sevilla, Madrid, Toledo) junto a Micaela, con la que mantuvo relación hasta 1608.

En 1605 Lope conoció a un importante personaje de la nobleza española, don Luis Fernando de Córdoba, sexto Duque de Sessa. Durante los 28 años a su servicio, el Fénix desempeñó las funciones de secretario y «alcahuete» (p. 100). Como es bien sabido, fue el duque una figura muy relevante a lo largo de la vida del dramaturgo: a la relación exclusiva mantenida entre los dos se debe el copioso y conocido epistolario, obra que exhibe la vertiente más íntima, exuberante y curiosa de la vida del Fénix y de su relación con el Duque de Sessa. Algunas cartas de alta relevancia serán comentadas por Arellano y Mata en el capítulo dedicado al fenómeno del mecenazgo relacionado con la actividad literaria del poeta madrileño (pp. 179-190). Termina el capítulo con la relación de la crisis espiritual sufrida por Lope en 1608: ingresa en la Congregación de Esclavos del Santísimo Sacramento, renuncia a sus pasiones y finalmente vuelve al hogar familiar.

En el penúltimo capítulo de la trayectoria vital y literaria del poeta, los dos editores subrayan dos aspectos principales: la ordenación sacerdotal en 1614 y la «gran pasión de madurez» (p. 124) con Marta de Nevares. La colección de las Rimas sacras fue «el resultado lírico de esa honda crisis espiritual» (p. 121). Sin embargo, la impetuosa pasión por la mujer casada de Alcalá, la Amarilis literaria, le empuja hacia una nueva y sacrílega aventura amorosa alrededor de 1616. La relación entre los dos dura muchos años, hasta cuando, en 1632, Marta de Nevares fallece después de una larga enfermedad. Las epístolas enviadas a Sessa y sus publicaciones poéticas recogen la desesperación que el deceso de su enamorada le provocó en el alma. La historia con Marcia Leonarda fue la más honda pasión vivida por el poeta y 
también la más Ilena de sentimientos trágicos. Arellano y Mata los evocan a través de algunos fragmentos de sus obras precisamente al concluirse el apartado.

Los dos editores prosiguen con el relato de la última parte del recorrido vital y profesional del dramaturgo: se trata del periodo en el que Lope experimenta «cansancio literario y desengaño vital» (p. 151). Es un intervalo temporal, el que va desde 1629 hasta 1635, durante el cual «los pájaros nuevos» empiezan a emerger en el ambiente literario de la época. Frente al nuevo bullicio intelectual, representado en primer lugar por Calderón, el genio de Lope no parece debilitarse: su talento no se apaga, y de hecho, en su postrer ciclo literario -el que Juan Manuel Rozas llama «de senectute»- sigue siendo excepcional (basta recordar una de las obras más reconocidas por la crítica, El castigo sin venganza, escrita en esta etapa, precisamente en 1631). Pero, a pesar de esta extrema luz creativa, «todos los biógrafos destacan el cansancio y la soledad del otrora vital Lope, que a sus 72 años encuentra su casa de la calle Francos vacía, fría y silenciosa» (p. 158); Lope muere el 27 de agosto de 1635. Arellano y Mata dejan que sea su primer biógrafo, Juan Pérez de Montalbán, el narrador de los últimos momentos de vida del gran poeta. Son los pormenores, los detalles particulares que Montalbán ofrece en la Fama póstuma los que adornan las últimas páginas de este apartado del volumen: después del conmovedor relato del momento del fallecimiento del poeta, Montalbán refiere incluso datos muy precisos sobre la ceremonia fúnebre tomada a cargo por el Duque de Sessa. Y, finalmente, su amigo recuerda que «las calles estaban tan pobladas de gente, que casi se embarazaba el paso al entierro, sin haber balcón ocioso, ventana desocupada ni coche vacío» (p. 163).

Concluido el viaje exploratorio por las intrincadas vías de la biografía lopesca, en el capítulo «La lucha por la vida y por la fama» (pp. 169-221) los dos autores se dedican al interesante asunto del mecenazgo nobiliario, fenómeno que marcó muy de cerca la vida y la obra del Fénix. Como ya hemos dicho anteriormente, la relación entre Lope y el Duque de Sessa es la que Arellano y Mata sondean más; sin embargo, los editores no olvidan mencionar las precedentes ligazones del poeta con otros importantes aristócratas de la época: con don Jerónimo Manrique (obispo de Ávila), con don Antonio de Toledo (Duque de Alba), con don Francisco de Ribera Barroso (Marqués de Malpica) y con don Pedro Fernández de Castro (Marqués de Sarria y Conde de Lemos): cada uno de estos personajes ilustres selló una fase distinta de la trayectoria creativa y personal de Lope.

Muy interesante y también entretenido es el segundo apartado presente en el mismo capítulo, el titulado «Lope y el gremio literario» (pp. 190-221): en él, Arellano y Mata compilan un registro de las relaciones que Lope mantuvo con algunos de los protagonistas literarios de su época, catalogando de manera documentada las amistades y las enemistades del Fénix. Entre sus admiradores se alistan Juan Pérez de Montalbán, José de Valdivielso, Luis Vélez de Guevara, María de Zayas, Vicente Espinel, Guillén de Castro y Mira de Amescua. Con Francisco de Quevedo mantuvo Lope unas relaciones cordiales, así como demuestran las mutuas alabanzas en algunas composiciones poéticas. En cambio, palabras mordaces dedicó el Fénix a Juan Ruiz de Alarcón por causa de una deformación física del escritor 
novohispano que suscitaba hilaridad entre la gente. Entre Lope y Cervantes se describe una relación complicada, «de rivalidad, poco aprecio y algo de envidia mutua» (p. 201); a Tirso de Molina parece que el Fénix demostró muy poca estima, a pesar de la admiración que el fraile mercedario, en cambio, sentía por él. Con Calderón mantuvo el dramaturgo madrileño una fría relación por considerarlo un temible adversario literario. Por último, Arellano y Mata consideran que merecería la pena realizar un análisis más detallado de la compleja relación de desprecio entre Lope y Góngora por las implicaciones que su antagonismo tuvo en el entorno literario del tiempo. Acerca de la reconocida enemistad entre los dos, comentan que «no se trata ya solo de actitudes personales, sino del enfrentamiento de dos modos de concebir la poesía» (p. 213).

Cierra el volumen el capítulo «La obra de Lope» (pp. 223-327): Arellano y Mata recorren detalladamente la trayectoria literaria del Fénix, estructurando la sección a través de tres apartados distintos que corresponden esencialmente a las ramas principales de la producción lopesca (poesía, prosa y teatro). El rigor científico, por un lado, y la agilidad de la narración, por otro lado, contribuyen a que el apartado resulte ser un provechoso recurso de estudio para el lector interesado. Además, en el subcapítulo dedicado al teatro, se distingue una parte que se dispone a modo de útil guía pedagógica sobre los principales aspectos que abarca el fenómeno del teatro comercial barroco español (los espacios de representación, las compañías y los actores, la organización de la fiesta teatral, la puesta en escena).

En conclusión, el volumen de Arellano y Mata destaca por su solvencia a la hora de entregar una trayectoria bio-bibliográfica lopeveguesca brillante, completa y precisa, redactada con una prosa actual, ágil y sencilla. El trabajo, de corte divulgativo y erudito a la vez, es sin duda merecedor de atención por su nítida propensión a la observación pormenorizada de muchos aspectos de la vida y de la obra del Fénix. Está claro que la personalidad del ilustre dramaturgo madrileño fue tan paradójica e histriónica que no hay manera de encerrarla por completo en las líneas de una narración biográfica; sin embargo, creemos que con su obra los dos editores navarros han conseguido seguramente un objetivo, o sea, acompañar al lector, experto o no, hacia el redescubrimiento del sustancial papel que Lope de Vega desempeñó en la literatura española de su época y también, durante los siglos sucesivos, en toda la literatura universal: «su valor sigue vigente en nuestros días», comentan los autores, «y lo seguirá por los tiempos de los tiempos» (p. 330). 